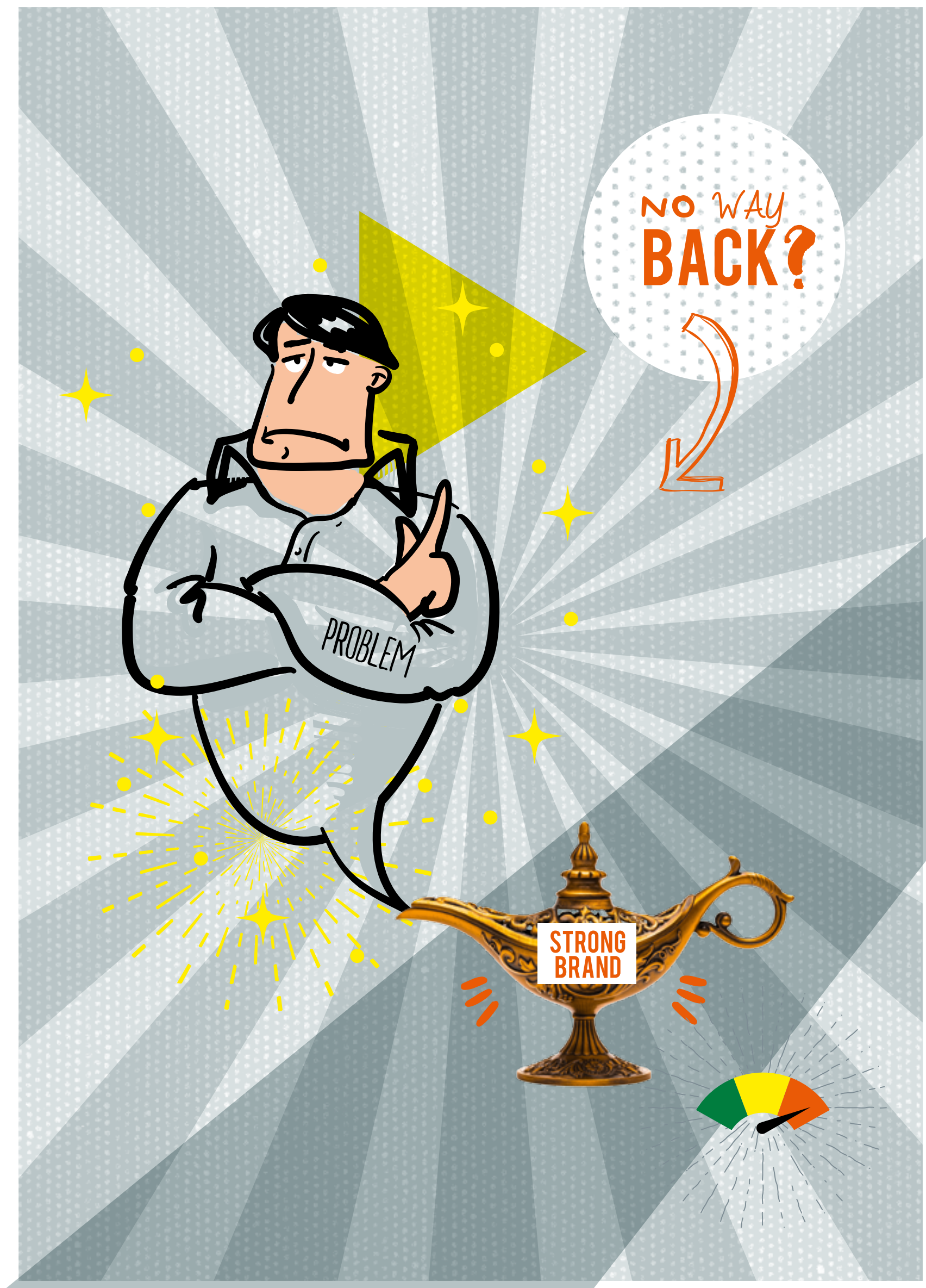




\title{
When Brand Familiarity Breeds Risk: The Curse of Negative Knowledge
}

\author{
Chip Walker
}

KEYWORDS

Brand Knowledge,

Brand Risk, BAV

THE AUTHOR

Chip Walker

Chip Walker Brand Strategy walker.chip@gmail.com
Knowing isn't liking /// Historically, marketers have been taught to believe that having more people know about a brand is always a good thing, and that there is no such thing as bad publicity. The common advice "just make sure they spell your name right" illustrates this thinking. But in today's world, knowing more about a brand can make people think worse of it. Rather than helping a brand, increased familiarity can actually add risk. This is a phenomenon referred to as "negative knowledge." The term "knowledge" not only means brand awareness or how many can recall a brand name. Rather, it refers to what people actually know or assume they know about a brand. Sources of brand knowledge range from personal experience to things they read or hear on the news to online chatter or word-of-mouth from friends.

We see the negative knowledge phenomenon happening in a wide range of categories: cable TV companies who consumers seem to love and hate, banks whose hidden fees regularly annoy or airlines whose customer treatment in coach grates on many passengers. To make matters worse, there's a growing risk that negative experiences will quickly spread, as consumers can now easily share their negative experiences online via Twitter and Facebook or consumer review sites like Rotten Tomatoes and Yelp.

Why brand knowledge can be problematic /// In BAV terms, "negative knowledge" happens when the knowledge pillar is higher than esteem - meaning the more consumers know about a brand, the less they like it. There are several reasons this can happen. 
$\{$ Box 1$\}$

\section{STUDYING EFFECTS OF BRAND KNOWLEDGE WITH Y\&R'S BRAND ASSET EVALUATOR (BAV)}

More than 20 years ago, Young\&Rubicam developed its Brand Asset Evaluator, which is the most widely used tool worldwide to assess the power of brand. The BAV enables managers to understand brand knowledge and three other aspects of brand equity: esteem, relevance and differentiation (see Figure 1).

Based on hundreds of studies across thousands of brands, the BAV researchers have found that there are patterns among these four pillars indicating a brand's strengths and weaknesses. Depending on the positioning on these pillars, brands vary in strength and potential and need to be managed differently for success. The strongest brands achieve high scores in all four dimensions. Being more relevant than different shows that a brand is commoditized and needs to focus on standing out. Being high on knowledge and lower in the other dimensions has shown to be an indicator of brand risk.

FIGURE 1:

\section{Pillars of the Y\&R Brand Asset Evaluator}

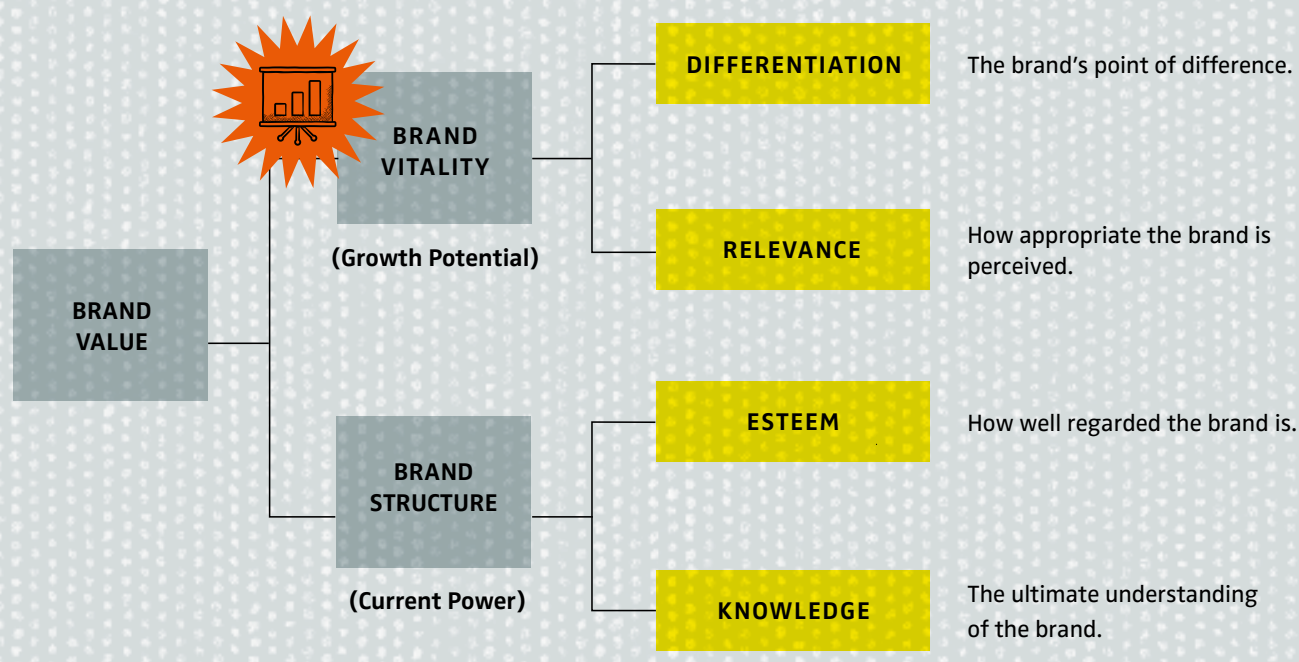

Figure from: http://www.valuebasedmanagement.net/methods_brand_asset_valuator.html 
Personal embarrassment /// Some brands with this pattern are "embarrassment brands" - brands consumers might be a little embarrassed if they were caught using or buying. Tabloids like the National Enquirer and, for some, restaurants like Hooters might fall into this category.

Bad customer experience /// Other brands with this pattern have less to do with social stigma and more with providing a bad real or perceived customer experience or being poor quality. In the world of services, Airlines and cable TV companies are good examples of this phenomenon. In retail and consumer goods, Pabst Blue Ribbon and K-Mart fall into the negative knowledge category.

\section{$\gg$ \\ In today's world, knowing}

more about a brand can make people think worse of it.

$\ll$

Socially undesired business motives /// Still other brands with this pattern have reputational problems, usually based on perceived "sins." These brands are seen as having bad motives - with big banks being a prime example. Also, brands in categories like big oil and cigarettes are seen by some as a net drain on society.

Different, but in a bad way /// In some cases, knowledge is greater than esteem but differentiation is also high. This means, "Your brand is different, but not in a good way." These are brands that for some reason just seem to rub some consumers the wrong way. Brands like Angry Birds, Hello Kitty and Crocs fall into this category.

It's worth noting that there are a few brands that actually feed on negative knowledge. These include sensationalistic brands like The Jerry Springer Show or The Howard Stern Show. The fact that they irk some people is, strangely, part of their appeal to others. But these brands are exceptions. Most brands with the negative knowledge problem need and want to do something about it.
What to do about negative brand knowledge /// Unfortunately, there are no quick fixes for negative knowledge. There is no list of five steps or four "how-tos" that will make the problem go away. We see brands that suffer for years and decades with this malady and some even go out of business under the weight of the problem. That's what happened to Oldsmobile, which was well known but couldn't shake its elderly user image.

Other brands do seem to be beating the negative knowledge rap - or are at least making some progress by finding a key that fits. Box 2 shows three examples, each tackling the problem from a different angle.

Be careful what you wish for /// A few years ago, I led an analysis at BAV looking at patterns of change in brand equity over 15 years. One of the most surprising findings was that we didn't identify any major patterns in which plummeting

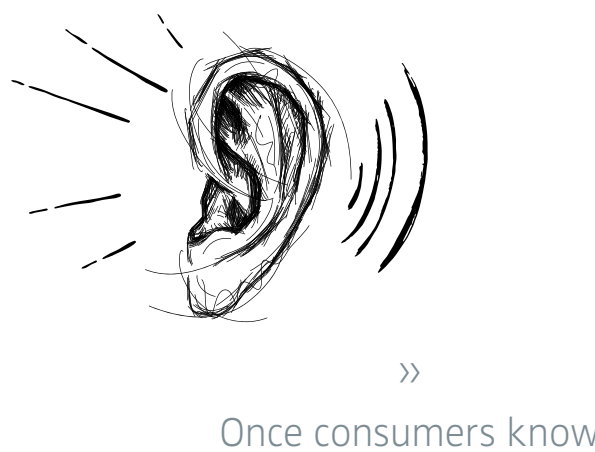

something about a brand, it is hard for them to "un-know" it.

$\ll$

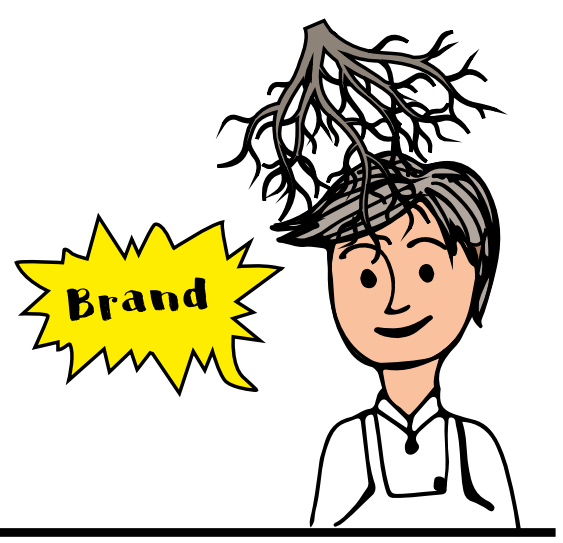




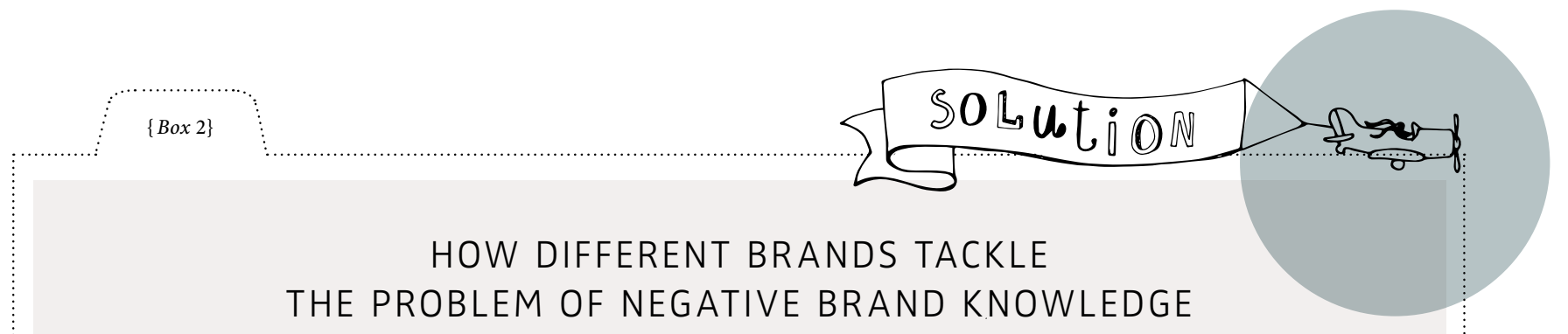

\section{Burberry: Reinvent yourself}

Former Burberry CEO Angela Ahrendts wrote in Harvard Business Review, "In luxury, ubiquity will kill you - it means you're not really luxury anymore. And we were becoming ubiquitous." Burberry had licensed everything from apparel to dog collars and was selling its signature trench coats in outlet malls at deep discounts. It had become known as a tired and sleepy brand, perhaps worn by one's father or grandfather. Ahrendts hired a "brand czar" who approved anything a consumer might see. Her strategy was to reinforce the brand's heritage, its Britishness, starting with the ethos of iconic "trench" - but expanding it stylishly into a range of luxury fashion. It took several years of effort, but, ultimately, it worked. By 2011, Burberry was named the fourth fastest-growing brand globally by Interbrand (behind Apple, Google and Amazon).

\section{Coca-Cola: Use your ubiquity as a platform}

Like Burberry, Coca-Cola had a ubiquity problem, but one of a different sort. Carbonated soft drinks have become villainized for high sugar content, and category leader Coca-Cola is the category's poster child. Thus, as a massive global brand with a huge number of current and past users, the brand's ubiquity made it seem like a mass globalizer of obesity. In 2013, Coca-Cola made a series of commitments that apply to more than 200 countries: offering low or no-calorie beverages everywhere, providing trans- parent nutritional information, starting programs to encourage exercise in every country and doing no advertising to children under 12 anywhere. By putting its considerable global marketing muscle behind these efforts, Coca-Cola is attempting to move from the leading cause of global obesity to a leading solution.

\section{Wal-Mart: Connect with your higher purpose}

Universally associated with low prices, Wal-Mart had become known for being the 500-pound gorilla that put mom and pop retailers out of business. It was also made fun of on websites like "People of Walmart.com," as being frequented by downscale people who were not aspirational in any way. In the mid-2000s, Wal-Mart rethought its "Always Low Prices" positioning and elevated it to feature the brand's higher calling: not just helping people save money, but helping them live better. More sophisticated advertising that gave a greater a sense of purpose to Wal-Mart's low prices, along with changes to store design and merchandising, has helped turn Wal-Mart's brand around. More recently, the brand has pushed into the realm of social responsibility, announcing that it is working to improve the welfare of farm animals in its supply chain. The WalMart brand is obviously not out of the woods, but it has clearly made progress in being known for more than cheap prices. knowledge was the primary problem. Knowledge seemed to stay with brands pretty stubbornly over time, even when esteem, relevance or differentiation were declining.

This reinforces the thesis about the dangers of negative knowledge: once consumers know something about a brand, it is hard for them to "un-know" it. During a time of media fragmentation when we're all struggling to gain more fame for our brands, it's critical to realize that it comes with a potential dark side. It's like putting the genie back into the bottle or the toothpaste back into the tube. While it's always wise to avoid brand obscurity, marketers must be ever cognizant that what customers know about a brand really can do more harm than good.

I. 